\title{
A Survey Paper on Implementing MTCMOS Technique in Full Subtractor Circuit
}

\author{
Tanvi Nagariya \\ M.Tech Student \\ NRI Institute of Information Science and \\ Technology, Bhopal, M.P, India
}

\author{
Braj Bihari Soni \\ Assistant Professor \\ NRI Institute of Information Science and \\ Technology, Bhopal, M.P, India
}

\begin{abstract}
This paper presents the study and survey analysis of Full Subtractor circuit on implementing the MTCMOS technique. Full Subtractor is a combinational circuit that performs subtraction and results in difference and borrows outputs. Implementing the MTCMOS technique on this circuit results in reduction of both leakage current and power consumption.
\end{abstract}

\section{Keywords}

Full Subtractor, MTCMOS, leakage current, power dissipation.

\section{INTRODUCTION}

In recent years, the usage of portable devices such as laptops, Smartphone, computers has been increased to great extent .The recognition and need of these portable electronic devices compels designers to aim for small silicon area, advanced speed, low power consumption and reliability. But these parameters are major concern in schematic design before their actual implementation in the layout. Thus minimum number of transistors should be used to consume limited area and power. In all digital circuits, arithmetic circuits play an important role. Subtractor is one of most significant and critical components of them. There are various possible logic styles compared to the basic CMOS logic style. Thus we focus on area and power efficient design of subtractor to design small portable devices .Low power VLSI design can be classified into two major categories: Analysis and Optimization. Both business and technical field interest in driven of low power chips and systems. With rapid expanding market, demand for low power electronic products is booming. Due to increased device density, speed and complexity semiconductor industries present rigorous requirements to power distribution of digital chips.

\section{SUBTRACTOR}

A subtractor is one of the four basic binary operations, which performs the subtraction. Subtractors are not only applied on arithmetic calculations, but in other parts of processor. It operates on binary numbers and results in binary numbers. Depending upon the purpose of the application to be performed, inputs vary. For two inputs, half subtractor is used and if we have three input we apply full subtractor to get the outputs.

\subsection{Full Subtractor}

A Full subtractor is a combinational circuit that performs a subtraction between two binary bits and can borrow 1 from lower significant stage. Thus circuit has three inputs and two outputs. Let A,B and Borrow in (Bin) be three inputs and two outputs Borrow out (bout) and Difference (Diff).It can be design by two 2-input EXOR gate, two 2-input AND gate, two 1 -input inverter and single 2 -input $\mathrm{OR}$ gate. The gate level of Full Subtractor has been shown in Figure 1 and Truth table 1.Booleanexpressions for the two output variables are obtained from karnaugh map.

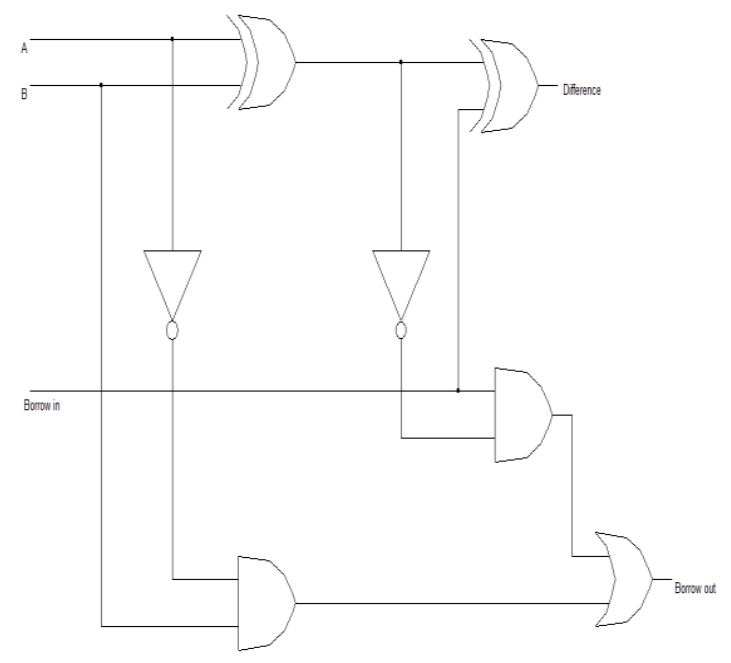

Figure 1. Gate-level Full Subtractor

Table 1. Truth table of Full Subtractor

\begin{tabular}{|c|c|c|c|c|}
\hline A & B & $\begin{array}{c}\text { Borrow in } \\
\text { (Bin) }\end{array}$ & $\begin{array}{c}\text { Borrow out } \\
\text { (Bout) }\end{array}$ & $\begin{array}{c}\text { Difference } \\
\text { (Diff) }\end{array}$ \\
\hline 0 & 0 & 0 & 0 & 0 \\
\hline 0 & 0 & 1 & 1 & 1 \\
\hline 0 & 1 & 0 & 1 & 1 \\
\hline 0 & 1 & 1 & 1 & 0 \\
\hline 1 & 0 & 0 & 0 & 1 \\
\hline 1 & 0 & 1 & 0 & 0 \\
\hline 1 & 1 & 0 & 0 & 0 \\
\hline 1 & 1 & 1 & 1 & 1 \\
\hline
\end{tabular}

Boolean expressions are -

1. Difference $=A \phi B \phi B_{\text {in }}$

$$
=A B B_{\text {in }}+A^{\prime} B^{\prime} B_{\text {in }}+A^{\prime} B B_{\text {in }}{ }^{\prime}+A^{\prime} B_{\text {in }}{ }^{\prime}
$$

2. Borrow $=A^{\prime} B^{\prime}+A^{\prime} B_{\text {in }}+B B_{\text {in }}$

$$
=A B B_{\text {in }}+A^{\prime} B^{\prime} B_{\text {in }}+A^{\prime} B
$$

\section{DIFFERENT PARAMETERS}

The performance assessment of full subtractor is established on area and power consumption, power delay, power dissipation and Power-Delay-Product. Area, speed and power consumption are the main issues in VLSI design which conflict with each other and act as constrain on the design of VLSI circuits. On the basis of different logic styles, various designs of full subtractor are individually investigated, analyzed on these performance criteria. 


\subsection{Power Parameter calculation}

Due to lower power dissipation in Complementary MetalOxide Semiconductor (CMOS), it has advantage over other completing technologies like Transistor- Transistor Logic (TTL) and Emitter Coupled Logic (ECL). Multiple Threshold CMOS (MTCMOS) isolates low threshold circuits from power and ground support using high threshold devices. Power dissipation is approximately proportional to the square of voltage supply. Thus lowering the supply voltage is the most competent way to achieve low power performance. To maintain the switching speeds of high transistors we need to scale down the threshold voltage. But this causes the significant amount of leakage power dissipation even when the transistor is not switching.

The main parameters that contribute to the total power dissipation are dynamic power, static power and short-circuit power. The expression can be stated as below-

$\mathrm{T}_{\text {total }}=\mathrm{P}_{\text {dynamic }}+\mathrm{P}_{\text {static }}+\mathrm{P}_{\text {short-circuit }}$

\subsubsection{Dynamic Power Dissipation}

It attributes mainly in the power dissipation. Due to capacitive charging and discharging of the output wiring and when transistor switches state from $\mathrm{ON}$ to $\mathrm{OFF}$ and vice versa, causes the dynamic power dissipation. Short circuit current is produced when there is no load capacitance. With the hike in capacitive load, charge and discharge current starts prevailing the main current.

$\mathrm{P}_{\text {dynamic }}=\mathrm{K} \cdot \mathrm{C} \cdot \mathrm{V}_{\mathrm{dd}}^{2} \cdot \mathrm{F}_{\mathrm{sw}}$

Where,

$$
\begin{array}{ll}
\mathrm{K} & =\text { Technology factor } \\
\mathrm{C} & =\text { Capacitance of switching nodes } \\
\mathrm{V}_{\mathrm{dd}} & =\text { Supply voltage } \\
\mathrm{F}_{\mathrm{sw}} & =\text { Effective switching frequency }
\end{array}
$$

The equation of dynamic power dissipation can be constructed with the assumption that rise time and fall time of the step input is much less than the repetition period. The above equation represents that the average dissipated power is proportional to energy required to charge and discharge the capacitance load.

\subsubsection{Short Circuit Power Dissipation}

Short circuit power is part of dynamic power consumption, it relied on signal transition. It occurs due to rise time and fall time of signal. For short period of time PMOS and NMOS are $\mathrm{ON}$, so there will be a path from $\mathrm{V}_{\mathrm{dd}}$ to $\mathrm{V}_{\mathrm{ss}}$. Therefore it is factor of supply voltage and directly proportional to $\mathrm{V}_{\mathrm{dd}}$. With the reduction in $V_{d d}, t_{r}$ and $t_{f}$ parameters will increase.

$\mathrm{P}_{\mathrm{sc}}=\mathrm{I}_{\mathrm{sc}} \cdot \mathrm{V}_{\mathrm{dd}} \cdot \mathrm{t}_{\mathrm{s}} \cdot \mathrm{f}_{\mathrm{sw}}$

Where,

$$
\begin{aligned}
& \mathrm{f}_{\mathrm{sw}}=\text { Switching frequency } \\
& \mathrm{I}_{\mathrm{sc}}=\text { Short circuit current } \\
& \mathrm{t}_{\mathrm{s}}=\text { Switching delay } \\
& \mathrm{V}_{\mathrm{dd}}=\text { Supply voltage }
\end{aligned}
$$

\subsubsection{Static Power Dissipation}

The static power dissipation is the product of leakage current and supply voltage. The total static power dissipation $\mathrm{P}_{\mathrm{s}}$ is given by

$\mathrm{P}_{\mathrm{s}}=\sum_{l}^{n}$ Leakage current $\times$ Supply voltage

Where,

$\mathrm{n}=$ Number of devices

\subsection{Leakage Current Calculation}

The leakage current equation can be represent as

$\mathrm{i}_{\mathrm{o}}=\mathrm{i}_{\mathrm{s}}\left(e^{q V / k T}-1\right)$

Where,

$i_{s}=$ Reverse saturation current

$\mathrm{V}=$ Voltage of diode

$\mathrm{q}=$ Electronic charge

$\mathrm{k}=$ Boltzmann constant

$\mathrm{T}=$ Temperature

Sub threshold or weak inversion conduction current between source and drain in a MOS transistor occurs when gate voltage is below the transistor threshold voltage. The Sub threshold or weak inversion current $\mathrm{I}_{\mathrm{ds}}$ can be written as-

$$
\begin{aligned}
& \mathrm{I}_{\mathrm{ds}}=\mathrm{I}_{\mathrm{dso}} e^{(\mathrm{Vgs}-\mathrm{Vt} / \mathrm{nVT})}\left[1-e^{V d s / V T}\right] \\
& \mathrm{I}_{\mathrm{dso}}=\mu_{\mathrm{eff}} \mathrm{c}_{\mathrm{ox}}(\mathrm{W} / \mathrm{L}) \mathrm{V}_{\mathrm{T}}^{2}
\end{aligned}
$$

Where,

$$
\begin{array}{ll}
\mu_{\mathrm{eff}} & =\text { Charge carrier mobility } \\
\mathrm{c}_{\mathrm{ox}} & =\text { Gate capacitance } / \text { unit area } \\
\mathrm{W} / \mathrm{L} & =\text { Width to length ratio of channel } \\
\mathrm{V}_{\mathrm{t}} & =\text { Threshold voltage } \\
\mathrm{V}_{\mathrm{T}} & =\text { Thermal voltage } \\
\mathrm{n} & =\text { Sub- threshold swing coefficient } \\
\mathrm{V}_{\mathrm{gs}} & =\text { Gate to source voltage } \\
\mathrm{V}_{\mathrm{ds}} & =\text { Drain to source voltage }
\end{array}
$$

\section{TRANSISTOR GATING}

In this technique two sleep transistor PMOS and NMOS are inserted in between supply voltage and ground. A PMOS is implanted in between pull-up network and network output. A NMOS is inserted in between pull down network and ground. During standby mode both sleep transistor are turned off. To reduce the voltage in power supply, method requires to reduce transistor threshold voltage to maintain noise margins and output. But this increases the sub threshold leakage current in $\mathrm{p}$ and $\mathrm{n}$ MOSFET's, increasing the overall power consumption. Thus transistor gating technique is implemented to reduce the power dissipation and leakage current. MTCMOS (Multi Threshold CMOS) technique has two main features:

(1) Two operational modes, active and sleep mode to organize the power management.

(2) Two dissimilar threshold voltages cutting off the low $\mathrm{V}_{t}$ from power supply and high $\mathrm{V}_{\mathrm{t}}$ from ground circuit. 


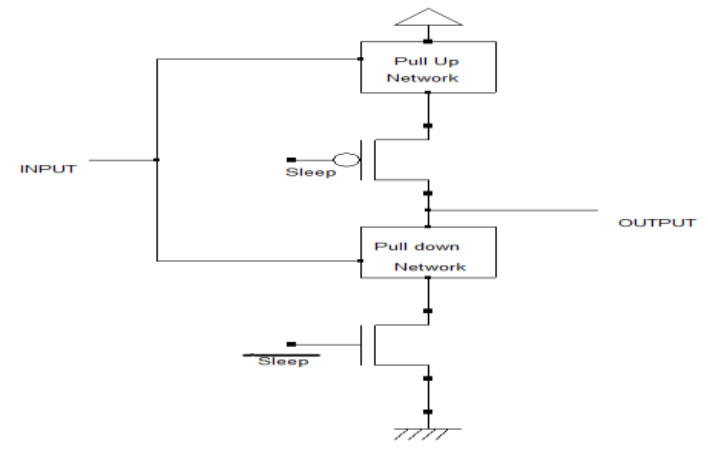

Figure 2. Transistor Gating Technique

\section{LITERATURE SURVEY}

[1] In 2012, Milind Gautam, Shyam Akashe proposed Transistor Gating technique implemented in Full subtractor circuit. In this paper, low-power design techniques proposed to minimize the standby leakage power in nanoscale CMOS. The tool used for schematic simulation is CADENCE VIRTUOSO in $45 \mathrm{~nm}$ technology. This technique results in reduction in leakage current by $17.58 \%$ and $24.38 \%$ reduction in leakage power.
[2] In 2015, Dr.PR Reddy, Dr. KV Ramanaiah, MM Basha presented different design circuit on full Subtractor implanting the MTCMOS technique. The tool used is Microwind $3 / \mathrm{DSCH}$ in $65 \mathrm{~nm}$ technology. The BSIM 4 parameter analyzer is used to analyze the proposed circuit. The proposed design of 14 transistor 1-bit Full subtractor at $1.0 \mathrm{v}$ results in power consumption of $1.896 \mu \mathrm{w}, \mathrm{I}_{\mathrm{ddmax}}$ is $0.197 \mathrm{~mA}$, area as $240 \mu \mathrm{m}^{2}$ and delay power calculated is $131 \mathrm{ps}$.

[3] In 2013, a paper presented by M. Gautam and S. Akashe on a full subtractor using MTCMOS technique to minimize the active leakage power. Simulation result is done at 0.7 volt designing on CADENCE VIRTUOSO tool in 45 nanometer technology. The proposed design results in reduction of leakage current by $15.63 \%$ and power is $95 \%$ compare to conventional full subtractor circuit.

[4] In 2015, S. Krishna, Raghu MC and S. Faris propose a paper intended to minimize leakage power and circuit area. The results were carried out in LT Spice and Microwind/DSCH software. Layout area required is 633.1 $\mu \mathrm{m}^{2}$ and noise power calculated as $33.89 \mathrm{pV}$.

Table 2. Literature Survey Table

\begin{tabular}{|c|c|c|c|c|c|}
\hline S. No & Journal & Topic & Technology & \multicolumn{2}{|c|}{ Parameter } \\
\hline & & & & $\begin{array}{c}\text { Power } \\
\text { consumption } \\
(\text { Reduction \%) }\end{array}$ & $\begin{array}{c}\text { Leakage current } \\
\text { (Reduction \%) }\end{array}$ \\
\hline [1] & $\begin{array}{l}\text { IEEE } \\
(2013)\end{array}$ & $\begin{array}{l}\text { Transistor gating: reduction } \\
\text { of leakage current and power } \\
\text { in full subtractor circuit. }\end{array}$ & $\begin{array}{l}\text { Cadence Virtuoso in } 45 \\
\mathrm{~nm}\end{array}$ & $\begin{array}{l}4.081 \times 10^{-3} \text { watt } \\
\text { in } 0.7 \mathrm{v} \\
(24.38 \%)\end{array}$ & $\begin{array}{l}280.2 \mathrm{pA} \\
(17.58 \%)\end{array}$ \\
\hline$[2]$ & $\begin{array}{l}\text { IEEE } \\
(2015)\end{array}$ & $\begin{array}{l}\text { Novel energy efficient 1-bit } \\
\text { full subtractor at } 65 \mathrm{~nm} \\
\text { technology }\end{array}$ & $\begin{array}{l}\text { Microwind / DSCH } \\
\text { in } 65 \mathrm{~nm}\end{array}$ & $\begin{array}{l}1.896 \mu w \text { att } \\
\text { in } 1.0 \mathrm{v}\end{array}$ & $\begin{array}{c}\mathrm{I}_{\mathrm{dd} \max }=0.917 \mathrm{~mA} \\
\mathrm{I}_{\mathrm{ddavg}}=0.002 \\
\mathrm{~mA}\end{array}$ \\
\hline [3] & $\begin{array}{l}\text { IEEE } \\
\text { (2013) }\end{array}$ & $\begin{array}{l}\text { Reduction of leakage current } \\
\text { and power in full subtractor } \\
\text { using MTCMOS technique }\end{array}$ & $\begin{array}{c}\text { Cadence } \\
\text { Virtuoso in } 45 \mathrm{~nm}\end{array}$ & $\begin{array}{l}1.4508 \mu \text { watt } \\
\text { in } 0.7 \mathrm{v} \\
(95 \%)\end{array}$ & $\begin{array}{c}228.65 \\
\text { fA } \\
(15.63 \%)\end{array}$ \\
\hline$[4]$ & $\begin{array}{l}\text { IJARECE } \\
\text { (2015) }\end{array}$ & $\begin{array}{l}\text { An efficient design of full } \\
\text { subtractor cell and its } \\
\text { application in ripple borrow } \\
\text { subtractor }\end{array}$ & $\begin{array}{l}\text { Microwind / DSCH 2, } \\
\text { LT Spice } \\
\text { in } 35 \mathrm{~nm}\end{array}$ & $\begin{array}{l}2.65 \text { milli watt } \\
\text { in } 0.7 \mathrm{v}\end{array}$ & - \\
\hline$[5]$ & $\begin{array}{l}\text { IJRECE } \\
(2014)\end{array}$ & $\begin{array}{l}\text { Reduction of leakage current } \\
\text { and power in full subtractor } \\
\text { using MTCMOS technique }\end{array}$ & LT Spice in $16 \mathrm{~nm}$ & $(98 \%)$ & $\begin{array}{l}\text { Active mode }=0.528 \mu \mathrm{A} \\
\text { Standby mode }=1.95 \mathrm{pA} \\
\text { in } 0.9 \mathrm{v}(45 \%)\end{array}$ \\
\hline$[6]$ & $\begin{array}{l}\text { IJSR } \\
(2014)\end{array}$ & $\begin{array}{l}\text { Power reduction approach in } \\
\text { combinational circuit }\end{array}$ & $\begin{array}{c}\text { Tanner } \\
\text { S-edit } 13.0 \mathrm{in} .25 \mu \mathrm{m}\end{array}$ & $\begin{array}{l}23 \text { milli watt } \\
\text { in } 5 \mathrm{v} \\
(78 \%)\end{array}$ & $3.2 \mu \mathrm{A}$ \\
\hline [7] & $\begin{array}{l}\text { IJESR } \\
(2014)\end{array}$ & $\begin{array}{l}\text { Static power dissipation } \\
\text { reduction on full subtractor } \\
\text { using MTCMOS }\end{array}$ & $\begin{array}{l}\text { Tanner S-edit } \\
\text { T-Spice in } \\
\text { TSMC018 }\end{array}$ & $\begin{array}{l}1.199 \times 10^{-8} \text { watt } \\
\text { in } 0.7 \mathrm{v} \\
(81 \%)\end{array}$ & - \\
\hline
\end{tabular}


[5] In 2014, MD Saroja and MR Naik proposed a paper to reduce the leakage current on implementing MTCMOS approach in full subtractor circuit. Reduction in current is almost $90 \%$ in $16 \mathrm{~nm}$ technology. Simulation result is executed at 0.9 volt for schematic and LT Spice for simulation in $45 \mathrm{~nm}$, $32 \mathrm{~nm}, 28 \mathrm{~nm}$ and $16 \mathrm{~nm}$ technology.

[6] In 2014, N. Rawat and R. Jain recommended a paper on power reduction approach in combinational circuit. MTCMOS way is implemented in which drain gating technique is used in proposed full subtractor circuit. The software for simulation used is Tanner S-edit 13.0.

[7] In 2014, k. Spandana and K. Sujitha proposed static power dissipation on full subtractor using MTCMOS technique. In this power gating is applied in full subtractor circuit using different leakage power reduction techniques like MTCMOS, Variable Body - Bias. The design software is Tanner S-edit and simulated under T- Spice tool in TSMC018 technology.

\section{CONCLUSION}

This survey paper analysis of Full Subtractor circuit can be concluded that reduction in power dissipation and leakage current is possible to great extent, on implementing the techniques like transistor gating, power gating and drain gating. In future, varying the W/L ratio in sleepy transistors results in change in total area of circuit. There is need to design the circuit in such a way that reduction in leakage current, power consumption and area can be minimized to maximum possible way.

\section{ACKNOWLEDGEMENT}

Author would like to thank NIIST Bhopal college for providing Microwind/ DSCH software to carry out thesis work and their valuable guidance from time to time.

\section{REFERENCES}

[1] Gautam M., Akashe S., "Transistor gating: reduction of leakage current and power in full subtractor circuit." Advance Computing Conference (IACC), 2013,pp 15141517.

[2] Basha MM., Dr.Ramanaiah KV, Dr.Reddy PR, "Novel energy efficient 1-bit full subtractor at $65 \mathrm{~nm}$ technology"
Electrical, Electronics, Signals, Communication and Optimization (EESCO), 2015.

[3] Gautam M., Akashe S., "Reduction of leakage current and power in full subtractor using MTCMOS technique" Computer Communication and Informatics (ICCCI), 2013.

[4] Krishna S., Raghu MC and Faris S., "An efficient design of full Subtractor cell and its application in ripple borrow subtractor" International Journal of Advanced Research in Electronics and Communication Engineering (IJARECE) Volume 4, Issue 5, May 2015, pp 14731476.

[5] Saroja MD, Naik MR, "Reduction of leakage current and power in full subtractor using MTCMOS technique" International Journal of Review in Electronics and Communication Engineering IJRECE (2014) Vol2, Issue 4, August 2014.

[6] Rawat N., Jain R. "Power reduction approach in combinational circuit (Half and full subtractor)" International Journal of Science and Research (IJSR) Volume 3, Issue 7, July 2014.

[7] Sandana K., Sujitha K., "Static power dissipation reduction on full subtractor using MTCMOS" International Journal of Engineering \& Science Research IJESR, July 2014, Vol-4, Issue-7,425-430.

\section{AUTHOR PROFILE}

Tanvi Nagariya has received her B.Tech degree in Electronics and Communication Engineering from NRI Institute of Information Science and Technology, Bhopal (M.P.). At present she is pursuing M.Tech in VLSI Design and Embedded System. Her area of interest includes low power VLSI design, embedded systems.

Braj Bihari Soni is working as Assistant Professor in NRI Institute of Information Science and Technology, Bhopal (M.P.).He has received his Bachelor of Technology from Nagaji Institute of Technology and Management, Gwalior, (M.P) and M.Tech degree from NRI Institute of Information Science and Technology, Bhopal, (M.P). 